\title{
HUBUNGAN MANAJEMEN PERPUSTAKAAN DAN MINAT BACA DENGAN PRESTASI AKADEMIK DI SEKOLAH TINGGI ILMU EKONOMI INDRAGIRI (STIE-I) RENGAT TAHUN AKADEMIK 2018-2019
}

\author{
DESI AMIDASTI \\ STIE Indragiri Rengat \\ Email: desiamidasti16@gmail.com
}

\begin{abstract}
This study aims to find out, the relationship between library management and academic achievement and the relationship between reading interest and academic achievement, at the Indragiri College of Economics (STIE-I) Rengat, Academic Year 2018-2019.The method used in this study is descriptive correlational method using a quantitative approach. The sample in this study were all students of the Indragiri (STIE-I) Rengat College of Economics totaling 169 students. Data were analyzed by Spearman Rank Correlation.The results showed that (1) There was no relationship between library management and academic achievement ( $p: 0.108>$ 0.05 ; (2) There was no relationship between reading interest and academic achievement ( $p: 0.477>0.05$. Academic achievement was also in influence by other factors.
\end{abstract}

\section{Keywords: Library Management, Reading Interest, Academic Achievement}

\section{Abstrak}

Penelitian ini bertujuan untuk mengetahui, Hubungan manajemen perpustakaan dengan prestasi akademik dan hubungan anatra minat baca dengan prestasi akademik, di Sekolah Tinggi Ilmu Ekonomi Indragiri (STIE-I) Rengat, Tahun akademik 2018-2019. Metode yang digunakan dalam penelitian ini adalah metode deskriptif korelasional dengan menggunakan pendekatan kuantitatif. Sampel dalam penelitian ini adalah seluruh mahasiswa Sekolah Tinggi Ilmu Ekonomi Indragiri (STIE-I) Rengat yang berjumlah 169 mahasiswa.Data dianalisis dengan Korelasi Rank Spearman. Hasil penelitian menunjukan bahwa (1) Tidak ada hubungan antara manajemen perpustakaan dengan prestasi akademik (p: 0,108>0,05; (2) Tidak ada hubungan antara minat baca dengan prestasi akademik (p: 0,477>0,05. Prestasi akademik juga di pengaruhi oleh faktor lain.

Kata Kunci : Manajemen Perpustakaan, Minat Baca, Prestasi Akademik

\section{PENDAHULUAN}

Perguruan tinggi merupakan lembaga pendidikan yang tidak akan berjalan baik apabila pendidikan maupun mahasiswa tidak didukung oleh sumber belajar yang diperlukan untuk menyelenggarakan kegiatan belajar mengajar yang bersangkutan. Salah satu sumber belajar yang penting adalah perpustakaan. Hal tersebut sesuai dengan Standar Nasional Pendidikan Perguruan Tinggi (No. 44 Tahun 2015 pasal 33), yang menjelaskan bahwa standar prasarana pembelajaran paling sedikit terdiri atas lahan, ruang kelas, perpustakaan, laboratorium / studio / bengkel kerja / unit produksi, tempat berolahraga, ruang untuk berkesenian, ruang untuk keagamaan, ruang unit kegiatan mahasiswa, ruang pimpinan perguruan tinggi, ruang dosen, ruang tata usaha, dan fasilitas umum lainnya sebagai penunjang kegiatan pembelajaran.

Mahasiswa yang rajin mengunjungi perpustakaan mempunyai peluang yang tinggi untuk meningkatkan minat bacanya. Apabila mengunjungi perpustakaan dengan tujuan membaca buku yang relevan dengan mata perkuliahan maka dapat berpengaruh pada nilai akademiknya. Dilihat dari hal itu perpustakaan memberikan kontribusi besar dalam menunjang proses pembelajaran sehingga diharapkan tujuan belajar mahasiswa akan tercapai. Oleh karena itu, dalam rangka mengoptimalkan peran perpustakaan khususnya dalam meningkatkan minat baca dan prestasi belajar, perpustakaan harus melakukan kegiatan 
layanan jasa perpustakaan yang efektif. Adapaun jumlah kunjungan mahasiswa ke Perpustakaan STIE-I Rengat, dapat dilihat pada tabel berikut ini ;

Tabel 1.

Jumlah Kunjungan Mahasiswa Ke Perpustakaan STIE-I Rengat

TA. 2014-2015 s.d. 2018-2019.

\begin{tabular}{|c|c|c|c|c|c}
\hline NO & $\begin{array}{c}\text { TAHUN } \\
\text { AKADEMIK }\end{array}$ & $\begin{array}{c}\text { JUMLAH } \\
\text { MAHASISWA }\end{array}$ & TARGET & REALISASI & $\%$ \\
\hline 1 & $2014-2015$ & 1,498 & 40,798 & 18,478 & 45 \\
\hline 2 & $2015-2016$ & 1,551 & 42,963 & 23,537 & 55 \\
\hline 3 & $2016-2017$ & 1,630 & 44,825 & 22,434 & 50 \\
\hline 4 & $2017-2018$ & 1,652 & 44,439 & 22,299 & 50 \\
\hline 5 & $2018-2019$ & 1,685 & 35,048 & 18,979 & 54 \\
\hline \multicolumn{2}{|c|}{ JUMLAH } & 8,016 & 208,072 & 105,727 & 51 \\
\hline
\end{tabular}

Sumber : Perpustakaan STIE-I Rengat, Data Olahan 2019

Berdasarkan data tabel tersebut diatas pencapaian realisasi kunjungan mahasiswa hanya $40 \%$, dari target yang di harapkan, hal ini menunjukan bahwa mahasiswa STIE-I Rengat, masih kurang berminat untuk berkunjung ke Perpustakaan.

Prestasi Akademik seseorang dapat didukung karena adanya faktor-faktor yang menunjang, antara lain seperti fasilitas ruang baca dan belajar yang nyaman, lancar membaca dan mudah memahami isi dari sebuah bacaan dari buku-buku pelajaran. Hal ini juga dilengkapi dengan fasilitas Perguruan Tinggi lain yang dapat menunjang prestasi belajar. Untuk dapat mengetahui prestasi akademik mahasiswa STIE-I Rengat TA. 2018-2019 dapat di lihat pada tabel berikut:

Tabel, 2.

Daftar Jumlah Mahasiswa dan Prestasi Akademik Mahasiswa STIE-I Rengat. TA. 2014-2015 s.d. 2018-2019

\begin{tabular}{|c|c|c|c|c|c|c|}
\hline \multirow{2}{*}{ NO } & TAHUN & JUMLAH & \multicolumn{4}{|c|}{ IPK } \\
\cline { 4 - 7 } & AKADEMIK & MAHASISWA & $<2,5$ & $2,5-2,9$ & $3,0-3,4$ & $3,5-4,0$ \\
\hline 1 & $2014-2015$ & 1,360 & 20 & 351 & 900 & 89 \\
\hline 2 & $2015-2016$ & 1,460 & 18 & 351 & 912 & 179 \\
\hline 3 & $2016-2017$ & 1,542 & 13 & 350 & 986 & 195 \\
\hline 4 & $2017-2018$ & 1,588 & 5 & 310 & 1,103 & 225 \\
\hline 5 & $2018-2019$ & 1,591 & 9 & 224 & 1,022 & 316 \\
\hline
\end{tabular}

Sumber : Staf Tata Usaha Kampus STIE-I Rengat, Data Olahan 2019.

Berdasarkan tabel tersebut diatas, bahwa prestasi akademik mahasiswa STIE-I Rengat, untuk TA. 2018-2019 sangat dominan pada IPK 3,0 s.d 3,4. Hal ini dimungkinkan ada hubunganya dengan minat baca mahasiswa dengan prestasi akademik. Berdasarkan uraian diatas, Maka penulis tertarik mengangkat judul penelitian dengan judul "Hubungan Manajemen Perpustakaan dan Minat Baca Dengan Prestasi Mahasiswa di Sekolah Tinggi Ilmu Ekonomi Indragiri (STIE-I) Rengat Tahun Akademik 2018-2019”. 


\section{TINJAUAN PUSTAKA DAN HIPOTESIS}

\section{Perpustakaan Perguruan Tinggi}

Menurut Hasugian (2009:79) menyatakan pengertian perpustakaan perguruan tinggi adalah Perpustakaan yang dikelola oleh perguruan tinggi dengan tujuan membantu terpenuhinya tujuan perguruan tinggi. Perpustakaan perguruan tinggi sebagai perpustakaan yang diselenggarakan oleh satuan pendidikan tinggi yang layanannya diperuntukkan sivitas akademika perguruan tinggi yang bersangkutan.

\section{Manajemen Perpustakaan}

Untuk mengelola sebuah perpustakaan diperlukan kemampuan manajemen yang baik, agar arah kegiatan sesuai dengan tujuan yang diinginkan. Kemampuan manajemen itu juga diperlukan untuk menjaga keseimbangan tujuan-tujuan yang berbeda dan mampu dilaksanakan secara efektif dan efisien.Pengetahuan dasar dalam mengelola perpustakaan agar berjalan dengan baik adalah ilmu manajemen, karena manajemen sangat diperlukan dalam berbagai kehidupan untuk mengatur langkah-langkah yang harus dilaksanakan oleh seluruh elemen dalam suatu perpustakaan. Oleh karena itu dalam proses manajemen diperlukan adanya proses perencanaan (planning), pengorganisasian (organizing), kepemimpinan (leadership), dan pengendalian (controlling). Di samping itu, manajemen juga dimaksudkan agar elemen yang terlibat dalam perpustakaan mampu melakukan tugas dan pekerjaannya dengan baik dan benar.

\section{Minat Baca}

Minat baca merupakan aktivitas yang dilakukan dengan penuh ketekunan dalam rangka membangun pola komunikasi dengan diri sendiri untuk menemukan makna tulisan dan menemukan informasi untuk mengembangkan intelektualitas yang dilakukan dengan penuh kesadaran dan perasaan senang yang timbul dari dalam dirinya.Oleh sebab itu, semakin tinggi minat baca seseorang, maka semakin kuat keinginannya untuk membaca.

\section{Prestasi akademik}

Prestasi akademik adalah sebuah kalimat yang terdiri dari dua kata, yaitu prestasi dan akademik, yang mana antara prestasi dan akademik mempunyai arti yang berbeda pula. Prestasi berasal dari bahasa Belanda yaitu prestatie yang artinya hasil usaha.Prestasi adalah hasil yang telah dicapai, dilakukan dan dikerjakan oleh seseorang (Baiti, 2010).

\section{Penelitian Terdahulu}

Siti Zuzinah. 2018. Hasil penelitian Ada hubungan yang signifikan manajemen perpustakaan dengan prestasi belajar siswa dibuktikan dengan hasil perolehan perhitungan regresi menunjukkan nilai t hitung sebesar 2,360 dengan probabilitas signifikansi adalah = 0,05 . Manajemen perpustakaan berpengaruh $\alpha 0,029$ berada lebih rendah dari dengan prestasi belajar siswa sebesar 19,0\%. 2) Ada hubungan yang signifikan minat baca dengan prestasi belajar siswa terlihat dari perolehan nilai t hitung sebesar 3,441 $=0,05$. Minat $\alpha$ dengan probabilitas signifikansi adalah 0,007 berada lebih kecil dari baca siswa berpengaruh dengan prestasi belajar siswa sebesar 11,5\%. 3) Ada hubungan yang signifikan antara manajemen perpustakaan dan minat baca secara bersama-sama dengan prestasi belajar siswa dibuktikan dari hasil perolehan nilai $F$ hitung $>F$ tabel $(4,928>3,520)$ dan signifikasi $<0,05(0,007<$ $0,05)$. Manajemen perpustakaan dan minat baca siswa berpengaruh dengan prestasi belajar siswa sebesar $15,7 \%$. 


\section{Kerangka Pemikiran}

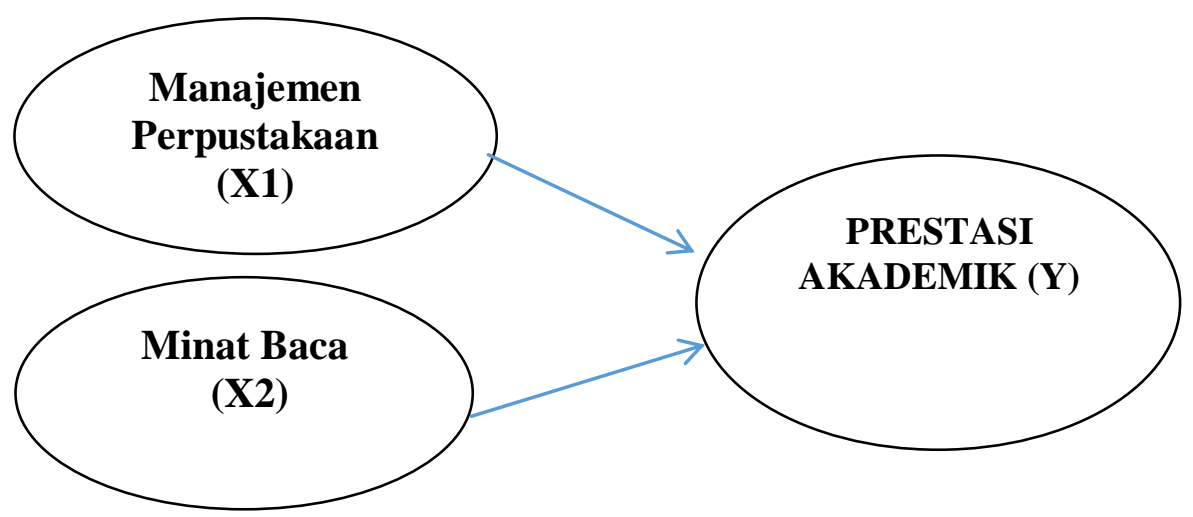

Gambar 1. Kerangka Penelitian

\section{Hipotesis}

1. Diduga ada hubungan antara manajemen perpustakaan dengan Prestasi Akademik di Sekolah Tinggi Ilmu Ekonomi Indragiri (STIE-I) Rengat Tahun Akademik 2018-2019.

2. Diduga ada hubungan antara minat baca dengan Prestasi Akademik di Sekolah Tinggi Ilmu Ekonomi Indragiri (STIE-I) Rengat Tahun Akademik 2018-2019.

\section{METODE PENELITIAN}

Tempat penelitian Sekolah Tinggi Ilmu Ekonomi Indragiri (STIE-I) Rengat, Populasi penelitian seluruh mahasiswa Sekolah Tinggi Ilmu Ekonomi Indragiri (STIE-I) Rengat Tahun akademik 2018-2019 dengan jumlah 1.685 Mahasiswa, sebagai sampel 169 mahasiswa dengan teknik proporsional Random Sampling, metode pengumpulan data kuesioner, dokumentasi, wawancara, Analisis data menggunakan metode Sperman Rank Correlatio, dengan mengunakan aplikasi SPSS versi 21.

\section{HASIL DAN PEMBAHASAN}

\section{Variabel X1 Manajemen Perpustakaan}

Untuk mengukur manajemen perpustakaan maka penulis menyebarkan kuesioner. Distribusi frekuensi tentang manajemen perpustakaan yang di dasarkan pada hasil penelitian dapat disajikan dalam tabel di bawah ini:

Tabel. 3

Distribusi Frekuensi Manajemen Perpustakaan

\begin{tabular}{|c|c|c|c|}
\hline Klasifikasi & Kelas interval & frekuensi & Frekuensi relatif \\
\hline Kurang baik & $25-26$ & 5 & $5 \%$ \\
\hline Baik & $27-28$ & 60 & $60 \%$ \\
\hline Sangat baik & $29-30$ & 35 & $35 \%$ \\
\hline & & 169 & $100 \%$ \\
\hline
\end{tabular}

Hasil perhitungan statistik deskriptif menemukan, manajemen perpustakaan STIEIndragiri mayoritas $60 \%$ berada pada klasifikasi baik, dan sisanya sebesar $35 \%$ berada dalam klasifikasi sangat baik dan 5\% berada dalam klasifikasi kurang baik. 
Volume VIII, No. 01, September 2019

Tabel 4. Output statistics manajemen perpustakaan

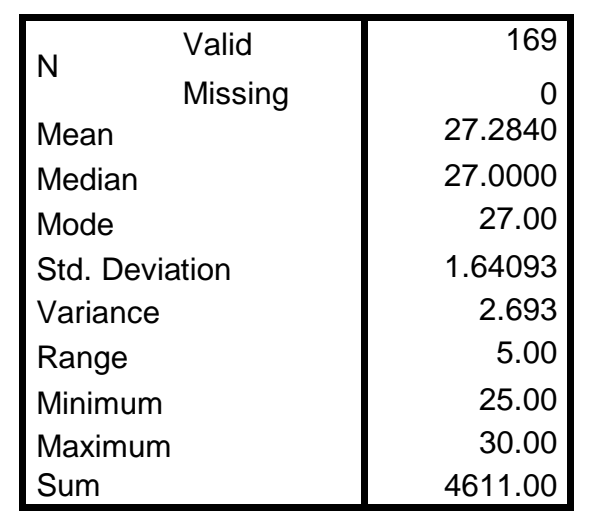

Hasil perhitungan statistik deskriptif diketahui mean; 27,28. Median; 27,00, mode; 27,00 dan standar deviasi 1,640. Distribusi pada klasifikasi Baik tersebut menjelaskan bahwa, 60\% mahasiswa STIE-Indragiri Rengat, berpendapat bahwa manajemen perpustakaan STIEIndragiri Rengat tergolong Baik.

\section{Variabel X2 Minat Baca}

Untuk mengukur tingkat Minat baca maka penulis menyebarkan kuesioner. Distribusi frekuensi tentang minat baca yang di dasarkan pada hasil penelitian dapat disajikan dalam tabel di bawah ini;

Tabel. 5.

Distribusi Frekuensi Minat baca

\begin{tabular}{|c|c|c|c|}
\hline Klasifikasi & Kelas interval & frekuensi & Frekuensi relatif \\
\hline Rendah & $14-20$ & 61 & $61 \%$ \\
\hline Sedang & $21-25$ & 73 & $73 \%$ \\
\hline Tinggi & $26-29$ & 35 & $35 \%$ \\
\hline & & 169 & $100 \%$ \\
\hline
\end{tabular}

Hasil perhitungan statistik deskriptif menemukan, Minat baca yang menyatakan rendah dengan Frekuensi 61 sebanyak 61\%, selanjutnya yang menyatakan sedang dengan Frekuensi 73 sebanyak $73 \%$ serta yang menyatakan tinggi dengan Frekuensi 35 sebanyak $35 \%$.

Tabel. 6. Output statistics Minat Baca

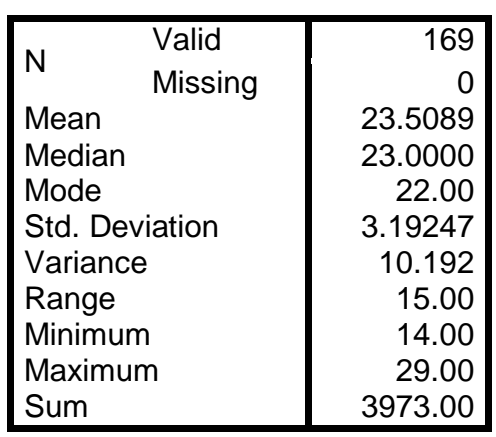


Hasil perhitungan statistik deskriptif diketahui mean; 23,50. Median; 23.00, mode; 22.00 dan standar deviasi 3.192. Hasil Pada klasifikasi sedang dengan jumlah $73 \%$ menjelaskan bahwa mahasiswa STIE-Indragiri Rengat, yang memiliki minat baca dalam kategori sedang.

\section{Variabel Y Prestasi Akademik}

Untuk mengukur Prestasi akademik dalam penelitian ini diukur dengan nilai indeks kumulatif. Distribusi frekuensi tentang prestasi akademik yang di dasarkan pada hasil penelitian dapat disajikan dalam tabel di bawah ini:

Tabel. 7.

Distribusi Frekuensi Prestasi Akademik

\begin{tabular}{|c|c|c|c|}
\hline Klasifikasi & Kelas interval & frekuensi & Frekuensi Relatif \\
\hline Cukup & $2,5-2,9$ & 35 & $35 \%$ \\
\hline Memuaskan & $3,0-3,4$ & 75 & $75 \%$ \\
\hline Sangat Memuaskan & $3,5-4,0$ & 59 & $59 \%$ \\
\hline & & 169 & $100 \%$ \\
\hline
\end{tabular}

Hasil perhitungan statistik deskriptif menemukan, prestasi akademik mahasiswa STIEIndragiri Rengat mayoritas $75 \%$ berada dalam klasifikasi Memuaskan.

Tabel 8. Output statistics Prestasi Akademik

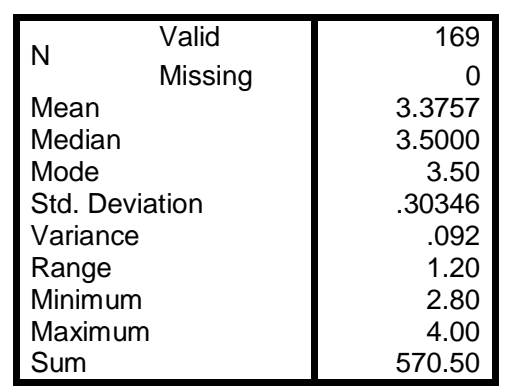

Hasil perhitungan statistik deskriptif diketahui mean; 3,37. Median; 3,50, mode; 3.50 dan standar deviasi 0,30 . Hasil pada klasifikasi memuaskan dengan jumlah $75 \%$ menjelaskan bahwa paling banyak adalah mahasiswa STIE-Indrgiri Rengat memiliki prestasi akademik memuaskan.

\section{Uji Validitas}

1. Hasil Uji Validitas variabel X1

Tabel 9. Hasil uji validitas Manajemen perpustakaan

\begin{tabular}{|c|c|c|c|}
\hline No. item & Sig & Sig hitung & Keterangan \\
\hline 1 & 0,05 & 0,000 & Valid \\
\hline 2 & 0,05 & 0,000 & Valid \\
\hline 3 & 0,05 & 0,000 & Valid \\
\hline 4 & 0,05 & 0,000 & Valid \\
\hline 5 & 0,05 & 0,000 & Valid \\
\hline 6 & 0,05 & 0,000 & Valid \\
\hline
\end{tabular}

Dari tabel hasil validitas variabel manajemen perpustakaan dapat di simpulkan sebagian besar valid karena sing $0,05<$ sing hitung 0,000 . 
Volume VIII, No. 01, September 2019

2. Hasil Uji Validitas variabel $\mathrm{X} 2$

Tabel 10. Hasil uji validitas Minat Baca

\begin{tabular}{|c|c|c|c|}
\hline $\begin{array}{c}\text { No. } \\
\text { item }\end{array}$ & Sig & Sig hitung & Keterangan \\
\hline 1 & 0,05 & 0,000 & Valid \\
\hline 2 & 0,05 & 0,000 & Valid \\
\hline 3 & 0,05 & 0,000 & Valid \\
\hline 4 & 0,05 & 0,000 & Valid \\
\hline 5 & 0,05 & 0,000 & Valid \\
\hline 6 & 0,05 & 0,000 & Valid \\
\hline
\end{tabular}

Dari tabel hasil validitas variabel minat baca dapat di simpulkan sebagian besar valid karena sing $0,05<$ sing hitung 0,000 .

\section{Uji Reliability}

1. Uji Realiability Variabel Manajemen Perpustakaan

Tabel 11. Hasil Uji Reliability

\begin{tabular}{|r|r|r|}
\hline \multicolumn{3}{|c|}{ Reliability Statistics } \\
Alpha & $\begin{array}{c}\text { Cronbach's } \\
\text { Alpha Based on } \\
\text { Standardized } \\
\text { Items }\end{array}$ & N of Items \\
\hline .518 & .604 & \\
\hline
\end{tabular}

Hasil ujiReliabilityCronbach's Alpha Based on Standardized Items, sebesar 0,604, maka indeks korelasi dan interprestasi Reliabilitas di kategorikan interprestasi agak rendah, dalam penelitian ini, manajemen perpustakaan Alpha>0,604, sehingga dapat dikatakan bahwa instrument dalam kuesioner ini reliabel.

\section{Uji Realiability Variabel Minat Baca}

Tabel 12. Hasil Uji Reliability

Reliability Statistics

\begin{tabular}{|r|r|r|}
\hline \multicolumn{1}{|c|}{$\begin{array}{c}\text { Cronbach's } \\
\text { Alpha }\end{array}$} & $\begin{array}{c}\text { Cronbach's } \\
\text { Alpha Based on } \\
\text { Standardized } \\
\text { Items }\end{array}$ & N of Items \\
\hline .549 & .631 & \\
\hline
\end{tabular}

Hasil uji ReliabilityCronbach's Alpha Based on Standardized Items, sebesar 0,631, maka indeks korelasi dan interprestasi Reliabilitas di kategorikan interprestasi Cukup, dalam penelitian ini, minat baca mempunyai Alpa $>0,60$, sehingga dapat dikatakan bahwa instrument dalam kuesioner ini reliable. 
Uji Normalitas

Hasil uji normalitas ;

Tabel 13. Uji Normalitas variabel Penelitian One-Sample Kolmogorov-Smirnov Test

\begin{tabular}{|c|c|c|}
\hline & & $\begin{array}{c}\text { Unstandardized } \\
\text { Residual }\end{array}$ \\
\hline $\begin{array}{l}\text { N } \\
\text { Normal Parameters } \\
\text { Most Extreme Differences } \\
\text { Kolmogorov-Smirnov Z } \\
\text { Asymp. Sig. (2-tailed) }\end{array}$ & $\begin{array}{l}\text { Mean } \\
\text { Std. Deviation } \\
\text { Absolute } \\
\text { Positive } \\
\text { Negative }\end{array}$ & $\begin{array}{r}169 \\
.0000000 \\
.30182555 \\
.134 \\
.070 \\
-.134 \\
1.736 \\
.085\end{array}$ \\
\hline
\end{tabular}

a. Test distribution is Normal.

b. Calculated from data.

One-Sample Kolmogorov-Smirnov Test

\begin{tabular}{|c|c|c|}
\hline & & $\begin{array}{c}\text { Unstandardized } \\
\text { Residual }\end{array}$ \\
\hline $\begin{array}{l}\text { N } \\
\text { Normal Parameters }{ }^{\mathrm{a}, \mathrm{b}} \\
\text { Most Extreme Differences } \\
\text { Kolmogorov-Smirnov Z } \\
\text { Asymp. Sig. (2-tailed) }\end{array}$ & $\begin{array}{l}\text { Mean } \\
\text { Std. Deviation } \\
\text { Absolute } \\
\text { Positive } \\
\text { Negative }\end{array}$ & $\begin{array}{r}169 \\
.0000000 \\
.30344914 \\
.183 \\
.091 \\
-.183 \\
2.373 \\
.000\end{array}$ \\
\hline
\end{tabular}

a. Test distribution is Normal.

b. Calculated from data.

Tabel 14. Rekap hasil uji Normalitas

\begin{tabular}{|l|l|l|l|c|}
\hline No & \multicolumn{1}{|c|}{ Variabel } & Signifikan & $\begin{array}{c}\text { Asymp. Sig. } \\
(2 \text {-tailed })\end{array}$ & Keterangan \\
\hline 1 & $\begin{array}{l}\text { Manajemen } \\
\text { Perpustakaan }\end{array}$ & 0,05 & 0,085 & Normal \\
\hline 2 & Minat Baca & 0,05 & 0,000 & $\begin{array}{c}\text { Tidak } \\
\text { Normal }\end{array}$ \\
\hline
\end{tabular}

Dari tabel normalitas diketahui bahwa variabel minat baca berdistribusi tidak normal namun variabel manajemen perpustakaan normal, maka pengujian hipotesis menggunakan uji statistic non parametris yaitu Korelasi Rank Sperman.

\section{Pengujian Hipotesis Penelitian}

Hasil pengujian hipotesis antara variabel manajemen perpustakaan dan minat baca dengan prestasi akademik di sajikan pada tabel di bawah ini;

Tabel 15. Hasil pengujian dengan variabel prestasi akademik

\begin{tabular}{|l|c|l|l|}
\hline \multicolumn{1}{|c|}{ Variabel Independen } & r-xy & Probalitas & Keterangan \\
\hline Manajemen perpustakaan & 0,124 & 0,108 & Hipotesis ditolak \\
\hline Minat baca & -0.055 & 0,447 & Hipotesis ditolak \\
\hline
\end{tabular}




\section{Hubungan Antara Manajemen perpustakaan dengan prestasi akademik}

Teknik analisis data yang digunakan untuk menguji hipotesis di atas adalah teknik analisis data korelasi pada statistic non parametric dari sperman. Pengujian hipotesis ini dikerjakan dengan bantuan program SPSS Ver 21. Berikut output analisis data penulis sajikan pada tabel berikut ;

Tabel 16. Correlations Manajemen Perpustakaan

\begin{tabular}{|c|c|c|c|c|}
\hline & & & $m p \_x 1$ & P_ad_Y \\
\hline \multirow{6}{*}{ Spearman's rho } & \multirow{4}{*}{$m p \_x 1$} & Correlation Coefficient & 1.000 & .124 \\
\hline & & Sig. (2-tailed) & & .108 \\
\hline & & $\mathrm{N}$ & 169 & 169 \\
\hline & & Correlation Coefficient & .124 & 1.000 \\
\hline & \multirow{2}{*}{ P_ad_Y } & Sig. (2-tailed) & .108 & \\
\hline & & $\mathrm{N}$ & 169 & 169 \\
\hline
\end{tabular}

Pada tabel diatas ditunjukan outputCorrelations, besarnya korelasi manajemen perpustakaan dengan prestasi akademik sebesar 0,124. Dengan tingkat $r$ : 0,124, menunjukan tingkat korelasi yang positif dan rendah. Korelasi yang positif artinya apabila Manajemen perpustakaan kurang baik maka prestasi akademik cukup.Korelasi yang rendah artinya manajemen perpustakaan bukan salah satu faktor utama yang mempengaruhi prestasi akademik mahasiswa.

Pada tabel di atas ditunjukan juga angka probabilitas 0,108. Oleh karena itu probabilitas lebih besar dari 0,05 (probabilitas 0,108>0,05) maka Ho gagal ditolak, yang artinya tidak ada hubungan antara manajemen perpustakaan dengan prestasi akademik.

\section{Hubungan antara Minat Baca dengan Prestasi Akademik}

Berikut output analisis data penulis sajikan pada tabel berikut ;

Tabel 17. Correlations Minat Baca

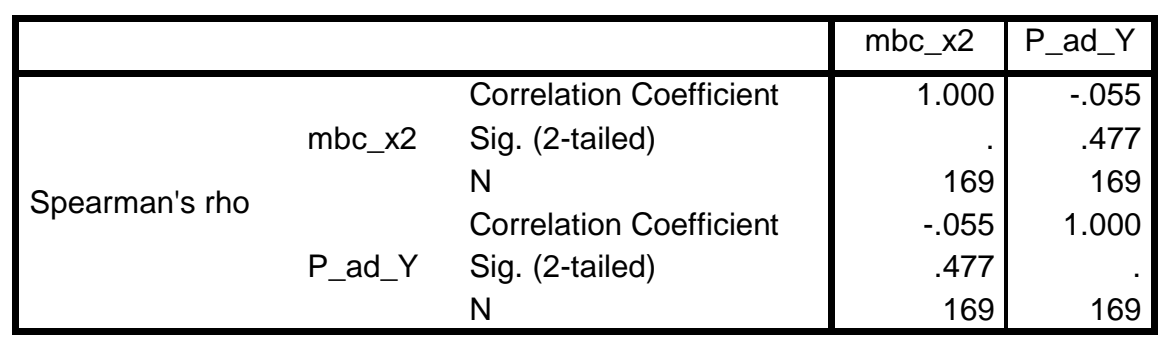

Pada tabel diatas ditunjukan outputCorrelations, besarnya korelasi Minat baca dengan prestasi akademik sebesar -0,055. Dengan tingkat korelasi $r=-0,055$, menunjukan tingkat korelasi yang negatif dan sangat rendah, korelasi yang negatif artinya apabila minat baca rendah maka prestasi akademik belum tentu rendah, korelasi yang negatif artinya minat baca bukan fkator utama yang mempengaruhi prestasi akademik mahasiswa STIE-Indragiri Rengat.

Pada tabel diatas juga ditunjukan angka (probabilitas 0,477>0,05) maka Ho gagal ditolak, yang artinya tidak ada hubungan antara minat baca dengan prestasi akademik. 


\section{b. Pembahasan}

\section{Hubungan antara manajemen perpustakaan dengan prestasi akademik.}

Dari hasil penyebaran kuisioner perihal manajemen perpustakaan, bahwa dari sampel 159 Mahasiswa STIE-Indragiri Rengat, 60\%, responden mengatakan Baik.Dan dari hasil analisis diketahui bahwa hipotesis yang mengatakan tidak ada hubungan antara manajemen perpustakaan dengan prestasi akademik mahasiswa STIE-Indragiri Rengat, ditolah yang artinya tidak ada hubungan antara manajemen perpustakaan dengan prestasi akademik.Walaupun manajemen perpustakaan baik, namun tidak ada hubunganya dengan prestasi akademik.

Hal ini menunjukkan prestasi akademik disebabkan oleh faktor-faktor selain manajemen perpustakaan, misalnya sarana prasarana kampus seperti ruang perkuliahan yang nyaman, terminal hospot, musolah, kantin, area parkir yang aman dan keamanan kampus.Penelitian oleh Siti Zuziah (2018) bahwa manajemen perustakaan secara parsial ada hubungan yang signifikan dengan perstasi belajar siswa.

\section{Hubungan antara minat baca dengan prestasi akademik}

Dari hasil penyebaran kuisioner perihal minat baca, bahwa dari sampel 159 Mahasiswa STIE-Indragiri Rengat, 73\%, responden minat bacanya Sedang.

Deskripsi data menujukan bahwa hubungan minat baca dengan prestasi akademik tidak ada.Hal ini menunjukan bahwa prestasi akademik disebabkan oleh faktor-faktor selain minat baca, misalnya motivasi, minat dan disipin dalam belajar, pendapatan orang tua, faktor jumlah dosen, kualitas dosen, biaya dan faktor lainnya. Dari 169 responden minat baca mahasiswa STIE-Indragiri Rengat, $35 \%$ tinggi, tetapi buka buku mata kuliah melainkan pada buku-buku lain misalnya buku motivasi, novel, koran dan majalah.

Penelitian ini sejalan dengan penelitian Adelina Romauli Haloho (2008) dengan hasil penelitian bahwa minat baca tidak ada hubunganya dengan prestasi akademik.penelitian oleh Siti Zuziah (2018) dengan hasil penelitian bahwa minat baca siswa secara parsial tidak ada hubungan yang signifikan dengan prestasi belajar siswa.

\section{Prestasi Akademik}

Dari hasil penyebaran kuisioner perihal pretasi akademik, bahwa dari sampel 169 Mahasiswa STIE-Indragiri Rengat, 75\%, responden prestasi akademiknya memuaskan. Hal ini membuktikan bahwa wakalupun, manajemen perpustakaan dan minat baca tidak ada hubunganya dengan prestasi akademik, namun prestasi akademik mahasiswa STIE-Indragiri kebanyakan pada kategori memuaskan.

\section{PENUTUP}

\section{Kesimpulan}

a. Manajemen perpustakaan tidak ada hubungan dengan prestasi akademik mahasiswa STIE-Indragiri Rengat TA. 2018-2019. Hal ini dibuktikan dengan hasil perolehan regresi Correlations, besarnya korelasi manajemen perpustakaan dengan prestasi akademik sebesar 0,124 .

b. Minta baca tidak ada hubungan dengan prestasi akademik mahasiswa STIEIndragiri Rengat TA. 2018-2019. Hal ini dibuktikan dengan hasil perolehan regresi output Correlations, besarnya korelasi Minat baca dengan prestasi akademik sebesar $-0,055$. 
c. Prestasi Akademik Mahasiswa STIE-Indragiri Rengat, memuaskan walaupun, manajemen perpustakaan dan minat baca tidak ada hubunganya dengan prestasi akademik.

\section{Saran}

a. Mahasiswa hendak dapat memanfaatkan fasilitas yang diberikan kampus, salah satunya perpustakaan sebagai sumber belajar.

b. Mahasiswa hendaknya menyadai arti penting dari membaca, karena dengan kegiatan membaca mahasiswa dapat meningkatkan pengetahuannya.

c. Menambah jumlah koleksi agar mahasiswa lebih banyak berkunjung ke perpustakaan

\section{REFERENCE}

Abidin, Yunus. 2010. Strategi Membaca, Teori dan Pembelajarannya. Rizqi Press. Bandung Ahmadi, Abu dan Supriyono, Widodo. 2010. Psikologi Belajar. PT Rineka Cipta. Jakarta Asmara. 2009. Prestasi Belajar. PT. Remaja Rosdakarya. Bandung.

Dewi Tri Hidayati.2017. Hubungan Minat Membaca Di Perpustakaan Sekolah Dengan Prestasi Belajar Siswa Mi Muhammadiyah Penaruban Purbalingga Tahun Pelajaran 2016/2017. Jawa Tengah.

Djamarah, Syaiful Bahri. 2011. Psikologi Belajar. PT. Rineka Cipta. Jakarta.

Dalyono. 2012. Psikologi Pendidikan. PT. Rineka Cipta. Jakarta.

Slameto. 2013. Belajar dan Faktor-faktor yang mempengaruhinya. Bumi Aksara. Jakarta.

Siti Zuzinah,2018. Hubunngan Antara Manajemen Perpustakaan dan Minat Baca Dengan Prestasi Belajar Siswa di Madrasah Tsanawiyah Muhamadiyah 10 Wedi Klaten Tahun Pelajaran 2016/2017.Joyakarta

Sardiman, A.M. 2012. Interaksi dan Motivasi Belajar Mengajar.PT.Raja Grafindo Persada. Jakarta

Suwarno, W. 2007.Dasar-dasar Ilmu Perpustakaan Sebuah Pendekatan Praktis. Arruzzmedia. Yogyakarta.

Suprizal.2013. Inovasi Manajemen Perpustakaan Sekolah Menengah Pertama (Studi Deskriptif Kualitatif di SMP Negeri 1 Kaur Selatan ).Bengkulu

Sardiman, A.M. 2012. Interaksi dan Motivasi Belajar Mengajar.PT.Raja Grafindo Persada. Jakarta

Sugiyono. 2016. Metode Penelitian Pendidikan Kuantitatif, Kualitatif dan R\&D. Alfabeta. Bandung.

Sukmadinata. 2011. Metode Penelitian Pendidikan. Remaja Rosda Karya. Bandung

Undang-Undang Republik Indonesia Nomor 20 tahun 2003.Tentang SistemPendidikan Nasional.Kemendikbud. Jakarta.

Winkel, WS. 2014. Psikologi Pendidikan dan Evaluasi Belajar. PT. Gramedia. Jakarta. 